\title{
NO PORTAL DA VELHICE: DIÁLOGOS COM O PASSADO*
}

\author{
Rosa Ferreira Novo ${ }^{* *}$
}

\section{INTRODUÇÃO}

Este trabalho tem como ponto de partida dados de um estudo mais alargado relativo ao Bem-Estar Psicológico (BEP), sua natureza e dinâmica no âmbito da personalidade, estudo realizado com mulheres na idade adulta avançada (Novo, 2000). Iremos abordar, na circunstância presente, em que medida o passado, ou a reconstrução que dele se faz, está relacionado com a vivência do BEP na idade adulta avançada. As diversas fases de vida após a meia-idade são distintamente consideradas e designadas na literatura, pelo que adoptámos como critério de identificação de idade adulta avançada o período que alguns autores designam de idosos-jovens, com idades entre os 65 e os 75 anos, isto é, no Portal da Velhice, fase de vida após a meia-idade e ainda não em plena velhice.

As duas áreas especialmente focadas - Idade Avançada e BemEstar - representam domínios de investigação que surgem na fase actual como alvos relevantes de estudo. Por um lado, a infância e a adolescência mobilizaram a atenção de teóricos e investigadores durante boa parte do século XX e só mais recentemente se tem intensificado o

* Trabalho que desenvolve o tema de uma comunicação apresentada no Encontro Internacional "Percursos no Feminino: Saúde e Psicopatologia da Mulher" (Porto, 25-27 de Outubro 2001). Lisboa.

"* Faculdade de Psicologia e de Ciências da Educação da Universidade de 
estudo em torno das pessoas idosas e do envelhecimento. Por outro lado, o interesse pelo Bem-Estar, a par de outras temáticas do domínio que Seligman e Csiksentmihalyi (2000) designam de Psicologia Positiva, afigura-se como promissor quando aplicado à idade mais tardia. Após décadas de estudo especificamente vocacionado para os aspectos ligados à deterioração funcional e à desertificação emocional e relacional nos idosos, surge a necessidade de se considerarem igualmente as potencialidades desta fase de vida e o modo como elas são influenciadas e podem influenciar a saúde, a satisfação de vida e a longevidade (Ryff, 1998).

$O$ facto de o estudo incidir numa amostra de um género apenas, 0 feminino, assinala a necessidade de a investigação atender às especificidades da vivência psicológica associada aos papéis biológico e social. O modo como as diferenças biológicas são interpretadas socialmente e elaboradas psicologicamente produz vidas com conteúdos e prioridades diferentes para homens e mulheres, o que justifica o estudo de amostras diferenciadas. A opção pelo género feminino resulta da oportunidade de obter testemunhos sobre as vidas que acompanharam as importantes transformações no papel da mulher, durante o século passado, na generalidade dos países ocidentais e, de um modo muito particular, na sociedade portuguesa.

\section{DELINEAMENTO DO ESTUDO}

A partir da identificação do espaço psicossocial de um grupo de mulheres, pretende-se analisar especificamente o modo como os diferentes papéis e funções exercidos no seio da família e no grupo social alargado, durante a meia-idade, se constituem como alicerces da identidade pessoal e do Bem-Estar Psicológico na idade avançada. Analisar-se-ão as variáveis mais relevantes e definidoras das vivências psicológicas associadas ao espaço pessoal, social e relacional das participantes, o que designámos de espaço psicossocial.

Proposto por C. Ryff (1989a; Ryff \& Keyes, 1995), o Bem-Estar Psicológico (BEP) é um constructo multidimensional que identifica os recursos cognitivos e afectivo-emocionais fundamentais aos sentimentos de felicidade e de satisfação de vida no contexto de um funcionamento psicológico positivo. Este constructo agrega seis dimensões (autonomia, aceitação de si, crescimento pessoal, objectivos na vida, do- 
mínio do meio e relações interpessoais positivas) consideradas importantes indicadores dos requisitos necessários à vivência de satisfação pessoal e à saúde mental. Cada uma das seis dimensões é operacionalizada através de uma escala de auto-avaliação, de tipo Likert, e o conjunto das escalas permite identificar um perfil dos diversos componentes do BEP (PWBS, Ryff, 1989b) e um nível global de BEP (Novo, 2000).

No estudo em referência, o BEP foi previamente avaliado, tendo por base a conjugação de dois critérios: o primeiro, os resultados nas escalas de auto-avaliação; e o segundo, os indicadores do Rorschach relativos à qualidade global do funcionamento e da adaptação psicológica. Com base no primeiro critério, foram diferenciados dois 'níveis', o de reduzido e o de médio/elevado BEP; este último nível veio a ser posteriormente diferenciado em duas categorias, com base no segundo critério, isto é, consoante estavam presentes ou ausentes, no Rorschach, índices de vulnerabilidade psicológica ${ }^{2}$. Assim, foi possível diferenciar três grupos de participantes, cada um identificando um 'tipo' de Bem-Estar: o Grupo 1, Bem-Estar Psicológico Reduzido (BEP-R); o Grupo 2, Bem-Estar e Vulnerabilidade Psicológica (BEPVP); e o Grupo 3, Bem-Estar Psicológico Global (BEP-G). Não obstante o estudo ter sido realizado com participantes 'normais', as participantes dos Grupos 1 e 2 vêm a revelar, embora de modo diverso, sinais de vulnerabilidade à depressão e de risco de descompensação psicológica. Ao longo da análise dos dados faremos referência a estes grupos por forma a identificar as variáveis psicossociais que melhor se associam a esta dimensão.

Os dados em análise neste trabalho foram obtidos mediante uma entrevista semi-estruturada (ver Novo, 2000) e implementada de acordo com um modelo clínico (Chiland, 1985; Perron, 1997). Os procedimentos de análise foram orientados no sentido de relevar uma eventual associação entre as diferentes variáveis definidoras do espaço psicossocial e o BEP das participantes, e também no sentido de explorar o papel que as variáveis do passado assumem no contexto das

${ }^{1}$ Escalas traduzidas e adaptadas para a população portuguesa (ver Novo, Silva e Peralta, 1997; Novo, 2000).

${ }^{2}$ A especificação dos critérios de BEP e de Vulnerabilidade Psicológica encontra-se descrita em Novo (2000). 
dimensões estruturais que agregam a variabilidade da matriz global dos dados.

\section{Caracterização da Amostra}

A amostra utilizada no estudo é constituída por 69 mulheres com idades entre os 65 e os 75 anos, residentes na zona da Grande Lisboa e com condições de vida autónoma. Ao nível da saúde, as condições físicas actuais foram consideradas normais e sem défices sensoriais ou problemas de saúde crónicos que implicassem redução da autonomia funcional. Do ponto de vista psíquico, as participantes não têm história psiquiátrica anterior, nem perturbação psicológica diagnosticada, e estão integradas socialmente de acordo com parâmetros correntes de normalidade.

O nível de escolaridade da amostra estudada é diverso, entre a instrução básica e uma formação superior, recaindo a mediana nos nove anos, nível superior ao da população portuguesa para coortes correspondentes $^{3}$. A escolaridade para estas coortes está longe de ser um indicador do nível sócio-cultural e/ou sócio-económico. Com efeito, o nível de escolaridade alcançado pelo sexo feminino, sobretudo na primeira metade do século XX, decorre de razões históricas e sociais muito diversas e só em condições muito específicas poderá constituir um indicador do nível cultural ${ }^{4}$.

${ }^{3}$ Apesar de não ser possível determinar com rigor o nível de escolaridade da população feminina para este grupo de idade, pode verificar-se a partir dos dados do INE de 1999 que, para o conjunto da população portuguesa com 65 ou mais anos de idade (em 1998), 53,1\% não tem qualquer nível de instrução completo, $36,6 \%$ concluiu o $1^{\circ}$ ciclo básico ( 4 anos de escolaridade), os restantes níveis de escolaridade apresentam percentagens reduzidas (e.g., 3,4\% para o ensino superior). Considerado o sexo feminino, os valores para as três categorias identificadas são de $70 \%, 23,5 \%$ e $2,3 \%$, respectivamente.

${ }^{4}$ Não é incomum, no caso de mulheres idosas, um nível de instrução básico a par de conhecimentos ou competências específicas que revelam um nível cultural mais diferenciado do que tal nível de instrução faria supor (e.g., domínio de línguas estrangeiras e formação musical específica). 
Os dois estados civis mais representados na amostra são os de casamento (35\%) e viuvez (33\%); as situações de divórcio/separação e de solteiro são menos frequentes ( $19 \%$ e $13 \%$, respectivamente). Não sendo possível identificar, nas estatísticas nacionais, a frequência por estado civil para este grupo específico de idades, podemos apenas considerar os dados para o grupo de idade superior a 64 anos, face ao qual a distribuição das diversas categorias de estado civil da nossa amostra se afasta 5 .

As características relativas ao estado civil, bem como à situação de coabitação, actividades desenvolvidas, papéis e funções actuais, religião e nível de integração social das participantes, consideradas nos três grupos anteriormente definidos, são apresentadas, sucintamente, no Quadro A (em anexo).

\section{Análise de Dados}

Seleccionados da entrevista os elementos essenciais, por um lado, à caracterização das condições e vivências do espaço social e relacional das participantes e, por outro, potencialmente associadas ao BEP, foram analisadas, numa primeira fase, vinte variáveis relativas aos seguintes domínios: Estado Civil; Agregado Familiar (Composição do Agregado e Grau de Satisfação com a situação de coabitação); Saúde (Estado actual e Grau de Preocupação); Papéis e Funções ${ }^{6}$ Actuais (Número e Grau de Satisfação); Papéis e Funções do Passado (Número e Grau de Satisfação); Actividades Actuais (Número e Grau de

${ }^{5}$ De acordo com as estatísticas oficiais, em $1998,54,8 \%$ da população feminina portuguesa com 65 ou mais anos vivia com cônjuge e cerca de $25 \%$ vivia só, com o estado de solteira, viúva ou separada/divorciada (INE, 1999).

${ }^{6} \mathrm{O}$ conceito de Papel aplica-se, no nosso estudo, quando existe uma interaç̧ão ou uma expectativa de interacção entre a pessoa em causa e a(s) do seu grupo familiar (e.g., conjugal ou maternal). O conceito de função aplica-se relativamente à interacção na esfera profissional, social ou cultural, considerando o exercício de Funções específicas e não o papel que eventualmente lhes possa estar subjacente. Só são consideradas as funções exercidas com carácter de regularidade e que impliquem responsabilidade perante terceiros (e.g., funções profissionais ou funções específicas de voluntariado em organizações culturais, religiosas ou políticas). 
Implicação); Relações Interpessoais (Familiares e de Amizade); Religião (Crenças e Práticas) e Investimento Futuro (Áreas de investimento e Manutenção ou Mudança das actividades de investimento actual).

Do ponto de vista analítico, e numa primeira fase, foi considerado o peso de cada uma das variáveis na diferenciação do tipo de BemEstar Psicológico (teste de homogeneidade do $\left.x^{2}\right)^{7}$. Posteriormente foram analisadas, a nível multivariado (método $\mathrm{HOMALS}^{8}$ ), as treze variáveis que do conjunto inicial se revelaram mais significativamente associadas ao BEP.

\section{Análise Univariada}

A análise dos dados relativos a cada variável de per se permite concluir que os Papéis e as Funções exercidas no grupo familiar e na esfera profissional, social ou cultural, durante a meia idade, estão associadas ao Bem-Estar vivido na idade adulta avançada. Não é o Número de Papéis ou de Funções exercidas no passado que se mostra particularmente relevante, mas o grau de Satisfação com o exercício dos mesmos. Relativamente aos papéis familiares (papel conjugal e papel maternal) eles mostram-se com um grau de associação diverso ao BEP: as relações de conjugalidade são claramente importantes no $\operatorname{BEP}\left[x^{2}(4,60)=20.26, p<.000\right]$, enquanto o papel maternal não se mostra associado a esta dimensão. Verifica-se, também, que a satisfação com o Papel Conjugal na meia-idade é avaliada de um modo diverso pelas participantes dos três grupos, e que o mesmo não acontece com a avaliação das relações maternais, em que há uma reduzida variabilidade da satisfação com o papel maternal do passado: na totalidade dos casos em que este papel está presente, a avaliação é sempre considerada como

${ }^{7}$ Método de análise univariada aplicado a dados organizados em tabelas de contingência e que permite identificar o grau de associação de cada variável com os três grupos de BEP considerados.

${ }^{8} \mathrm{~A}$ HOMALS é um método de análise multivariada que permite identificar dimensões estruturais dos dados, partilhando, em termos interpretativos, semelhanças com o de análise factorial em componentes principais. Este método possibilita a análise quantitativa e multivariada de variáveis categoriais e é apropriado à análise de múltiplos indicadores inter-relacionados de natureza qualitativa, duplo atributo do material de entrevista. 
satisfatória ou muito satisfatória. Tal pode constituir uma razão para a ausência de uma associação com o BEP.

No contexto das histórias de vida analisadas, verificámos que este papel é o mais valorizado entre todas as áreas consideradas. O Papel Maternal é investido de forte valor emocional para as participantes que foram mães, constituindo um núcleo importante da auto-estima e um alicerce da identidade pessoal, nunca posto em causa. Também no caso das participantes que, por razões diversas não tiveram filhos $(20 \%$ da amostra), a maternidade é abordada de um modo idealizado, como sendo uma oportunidade de realização pessoal e de apoio na velhice.

Já o grau de satisfação com o Papel Maternal actual, nos casos em que tal se verifica, mostra-se muito significativamente associado ao BEP $\left[\mathrm{x}^{2}(2,52)=21.58, p<.000\right]$, isto é, as relações que estas mulheres estabelecem com os seus filhos adultos está claramente relacionada com 0 nível de BEP de que desfrutam. A possibilidade de reconhecer que as relações actuais não são satisfatórias parece não constituir, neste caso, uma forte ameaça à auto-estima e à identidade. A relação com os filhos adultos é, porventura, entretecida num contexto distinto daquele que caracteriza as relações quando estes eram crianças, em que o progenitor assume, por inteiro, a responsabilidade de nutrir e estimular relações saudáveis, promotoras de envolvimento e desenvolvimento. $\mathrm{Na}$ verdade, nos testemunhos destas mulheres, sobretudo nos casos em que existem conflitos ou insatisfação com as relações estabelecidas com os filhos adultos, são escassas as referências a responsabilidades pessoais ou, quando muito, são tecidas considerações sobre alguns erros cometidos, mas predomina o reconhecimento das melhores intenções na educação dos filhos. Não é a competência como mãe que é directamente visada, são antes circunstâncias diversas que servem de justificativo à insatisfação com as relações com filhos adultos.

Relativamente às Funções exercidas no Passado fora do contexto familiar verifica-se, igualmente, uma relação positiva entre o grau de satisfação e o $\operatorname{BEP}\left[x^{2}(2,49)=9.84, p<.042\right]$. A maioria das participantes avalia de um modo positivo o exercício de funções no passado, designadamente de funções profissionais. A diferenciação reside, sobretudo, no grau que tal satisfação assume, registando-se nas participantes do Grupo 1 (BEP-R) uma menor frequência na categoria de elevada satisfação. Cerca de $30 \%$ das participantes não tiveram uma ocupação ou carreira profissional no passado, circunstância que, na maioria dos casos, é avaliada de modo negativo. As razões invocadas 
para esta apreciação não contemplam tanto a valorização de uma profissão em si, mas sobretudo os benefícios indirectos que uma actividade social formal pode proporcionar, com destaque para a autonomia pessoal, para a independência económica e para o alargamento da rede interpessoal.

Os resultados observados no domínio dos Papéis e Funções do Passado, papéis familiares e funções profissionais e sociais diversas, são interessantes e vão no sentido de trabalhos empíricos anteriores (e.g., Vanderwater, Ostrove, \& Stewart, 1997) que indicam a diversidade de papéis e de funções como facilitadores do desenvolvimento da identidade psicossocial, a qual, por sua vez, tem um papel preditivo na qualidade dos papéis futuros e no bem-estar pessoal. Neste sentido, não só a qualidade ou a satisfação no exercício de papéis importa, mas a quantidade de papéis e funções exercidas terá também impacto, embora de carácter menos directo, no BEP vivido em fases posteriores da vida.

O Grau de Satisfação com o Papel Conjugal surge, nesta rubrica, como o elemento mais fortemente associado ao Bem-Estar Psicológico $\left[x^{2}\right.$ $(4,60)=20.26, p<.000$ ] e indica um contraste entre os níveis de satisfação das participantes dos Grupos 1 e 3, isto é, indica a moderada satisfação como típica das participantes com reduzido BEP (Grupo 1), enquanto a elevada satisfação caracteriza as participantes com BEP Global (Grupo 3). O Grupo 2 (BEP-VP) regista uma posição intermédia, não se diferenciando estatisticamente de nenhum dos outros dois grupos, o que acontece com a generalidade das variáveis consideradas em entrevista (ver Quadro A).

\section{Análise Multivariada}

Na sequência da análise anterior procedeu-se à selecção das variáveis mais relevantes para uma análise multivariada, procurando avaliar o peso específico das variáveis do passado, face às da vida actual, na diferenciação do BEP.

Aplicado o método HOMALS à matriz de dados obtidos com o conjunto de treze variáveis que, em conjunto, se oferecem como potencialmente diferenciadoras dos indivíduos, foi possível extrair três dimensões estruturais que explicam cerca de $83 \%$ da variância dos dados, com as duas primeiras dimensões a serem responsáveis por $63 \%$ da variância. Os valores próprios editados pela HOMALS (ver Quadro 1) indicam a importância relativa de cada uma das 


\section{Quadro 1}

Medidas de Discriminação das Variáveis e Valores Próprios das Dimensões HOMALS

\begin{tabular}{|l|c|c|c|}
\hline \hline \multicolumn{1}{|c|}{ Variáveis } & Dimensão 1 & Dimensão 2 & Dimensão 3 \\
\hline \hline Estado Civil & .188 & .655 & .743 \\
\hline Composição - Agregado Familiar & .089 & .603 & .285 \\
\hline $\begin{array}{l}\text { Satisfação - Agregado } \\
\text { Familiar }\end{array}$ & .514 & .659 & .326 \\
\hline Saúde - Actual & .348 & .101 & .018 \\
\hline Saúde-Preocupação & .497 & .097 & .112 \\
\hline N. ${ }^{\circ}$ Papéis e Funções Actuais & .087 & .545 & .531 \\
\hline Satisfação c/ Papéis Actuais & .539 & .516 & .149 \\
\hline $\begin{array}{l}\text { N. }{ }^{\circ} \text { Papéis e Funções do } \\
\text { Passado }\end{array}$ & .083 & .342 & .415 \\
\hline Satisfação c/ Papéis Passado & .544 & .045 & .017 \\
\hline N. ${ }^{\circ}$ Actividades Actuais & .378 & .067 & .042 \\
\hline $\begin{array}{l}\text { Implicação - Actividades } \\
\text { Actuais }\end{array}$ & .430 & .087 & .002 \\
\hline Relações Familiares & .229 & .073 & .008 \\
\hline Relações Amizade & .420 & .001 & .000 \\
\hline \hline $\begin{array}{l}\text { VALORES PRÓPRIOS } \\
\text { (Lambda) }\end{array}$ & 4.35 & 3.79 & 2.65 \\
\hline \hline \begin{tabular}{l} 
\% VARIÂNCIA TOTAL \\
\hline \hline
\end{tabular} & 33.44 & 29.17 & 20.36 \\
\hline
\end{tabular}

Nota. As variáveis relativas à avaliação do Passado e os respectivos valores de saturação nas três dimensões estão destacados. A sombreado, assinalam-se as variáveis com medidas de discriminação mais elevados em cada uma das Dimensões. 
dimensões para explicar a dispersão informativa da matriz de input. Todavia, a grandeza do valor próprio de uma dimensão não é elucidativa de uma importância idêntica para todas as variáveis que a compõem, pelo que é o exame prévio das medidas de discriminação que permite conhecer o valor de cada variável no contexto das restantes. Deste modo, e conforme a síntese dos dados apresentados no Quadro em referência, verifica-se que: a Dimensão 1 apresenta um valor próprio elevado e é responsável pela explicação de cerca de $33 \%$ da variância da informação psicossocial; entre as variáveis que mais contribuem para a Dimensão 1, a Satisfação com os Papéis do Passado é aquela com um peso mais elevado (.544), seguida das variáveis relativas à Satisfação com os Papéis Actuais e com a Satisfação com o Agregado Familiar e de outras variáveis com menor valor de discriminação.

Relativamente à Dimensão 2, responsável por $29 \%$ da variância da matriz, o peso da variável Número de Papéis e Funções do Passado é modesto e surge na sequência das variáveis relativas aos Papéis Actuais, Estado Civil e Agregado Familiar. A Dimensão 3, que agrega cerca de $20 \%$ da variância, é também definida pelo variável Número de Papéis e Funções do Passado, a qual ocupa um lugar terciário, depois do Estado Civil e do Número de Papéis e Funções Actuais.

A análise do modo como as variáveis se agregam e do peso relativo de cada uma delas no contexto multivariado torna possível uma atribuição de sentido psicológico às dimensões que emergem da HOMALS. Verifica-se que, na Dimensão 1, o sentido que unifica as vivências psicológicas representadas pelas diversas variáveis é relativo à qualidade das relações estabelecidas, por cada um consigo próprio e com os outros. Na Dimensão 2, onde se agregam as variáveis que representam aspectos psicossociais decorrentes da relação com o núcleo familiar restrito (estado civil, composição e satisfação com o agregado familiar e papéis familiares) e com os papéis exercidos no passado e no presente, salienta-se a quantidade dos elementos do espaço relacional. As variáveis definidoras da Dimensão 3 apontam para a natureza mais descritiva da condição de vida ou do espaço social que cada sujeito ocupa (estado civil e papéis, aspectos já integrados nas dimensões anteriores, nomeadamente na segunda, deste modo, a Dimensão 3 não se reveste de particular valor interpretativo em si mesma e não introduz um acréscimo informativo à análise dos dados. Poderemos considerar que não é o modo como o espaço social é ocu- 
pado que importa, mas que é a vivência psicológica do mesmo e das relações a que dá lugar que assumem especial relevância.

Se atendermos à representação gráfica da distribuição dos indivíduos (Figura 1) e das diversas categorias por variável (Figura 2) ${ }^{9}$, e consideradas apenas as duas primeiras dimensões, podemos considerar que, enquanto a Dimensão 1 diferencia os indivíduos pela nature$\mathrm{za} /$ qualidade das vivências psicológicas associadas aos elementos do espaço psicossocial, a Dimensão 2 introduz uma diferenciação de cariz distinto, que assenta na presença/ausência ou na quantidade dos elementos do espaço relacional. Neste caso, a importância do elemento 'quantidade' poderá ser interpretada no sentido, já adiantado na fase anterior de análise, de que a diversidade de ocupações e de experiências, para as quais remetem o exercício de um maior número de papéis, constituem uma oportunidade para se desenvolver a satisfação, o sentimento de realização e de bem-estar pessoal.

Estas interpretações ganham mais sentido se atendermos à área definidora do Grupo 3 (BEP-G; representado maioritariamente no quadrante superior direito da Fig. 1) e às categorias que lhes estão associadas (representadas no quadrante superior direito da Fig. 2), onde se conjugam níveis de maior satisfação com maior número de papéis no passado e no presente. Reforçando esta linha interpretativa, a variável Actividades Actuais assinala também uma presença no mesmo sentido, em que o maior número de actividades está associado ao maior número de papéis e a maiores níveis de satisfação, assinalando, do mesmo modo, o espaço definido pelo grupo de BEP Global.

Uma outra característica suscitada pela representação gráfica é a relativa à eventual estabilidade de categorias com conteúdo idêntico, mas em que varia o foco temporal consoante remetem para o presente ou para o passado. As variáveis nestas condições são o Número de Papéis e a Satisfação com os mesmos, na situação Actual e no Passado. A leitura do posicionamento das categorias a que as quatro variáveis se referem (ver Fig.2) indica a proximidade entre o número de papéis no passado e no presente, entre categorias equivalentes (e.g., PA1 e PP1, $\mathrm{n}^{\circ}$. restrito de Papéis Actuais e do Passado; PA3 e PP3, $\mathrm{n}^{\circ}$. amplo de Papéis Actuais e do Passado). A proximidade das categorias sugere

${ }^{9}$ A descrição dos códigos das diversas categorias de variáveis apresentadas na Figura 2 encontra-se no Quadro B (em anexo). 


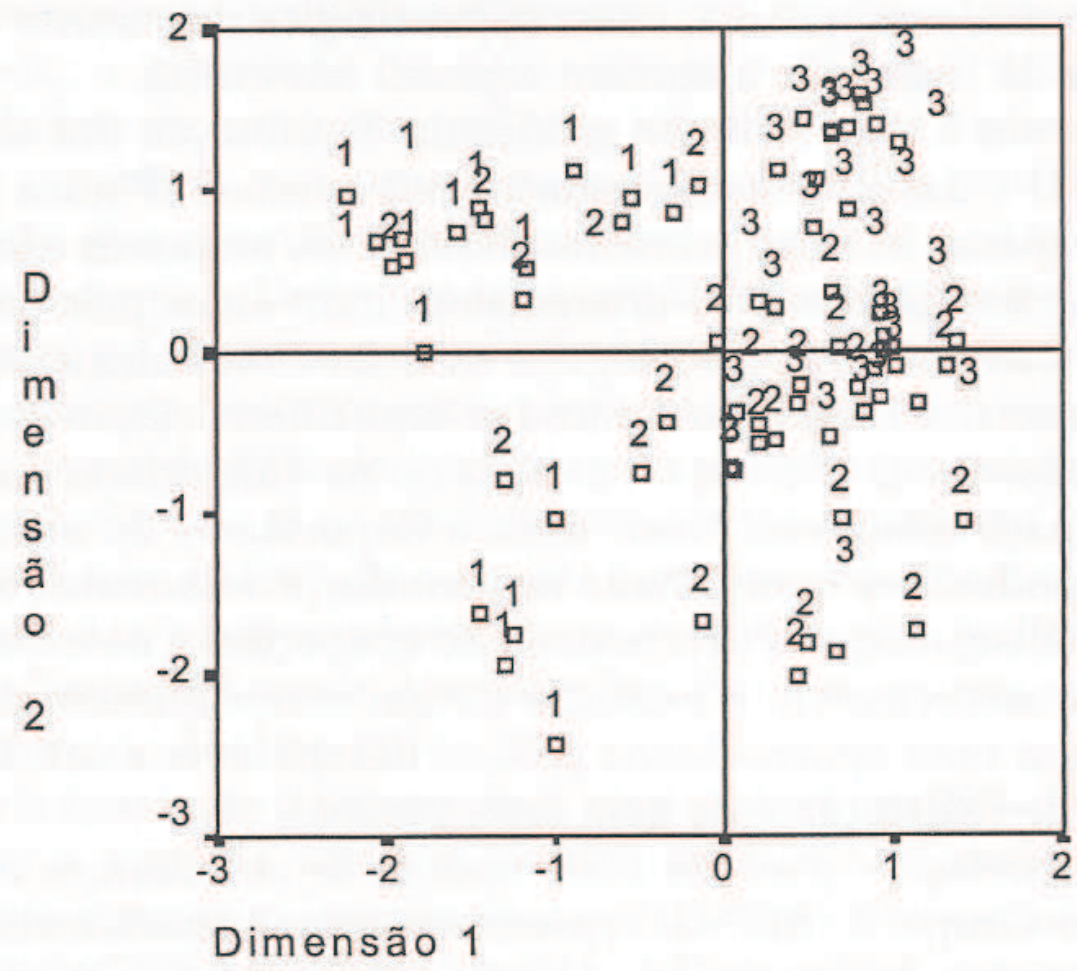

Figura 1

Configuração Topológica do Espaço Psicossocial: Projecção dos Indivíduos por Grupo de Bem-Estar Psicológico

que as participantes que as ocupam têm características próximas, pelo que, atendendo ao referencial passado-presente, indicia uma fraca mobilidade temporal.

$\mathrm{O}$ mesmo tipo de leitura aplicado às variáveis relativas à satisfação dá-nos a conhecer uma maior mobilidade, sobretudo quando a avaliação do passado é insatisfatória. As categorias que representam esta mobilidade temporal são a PPMi e PAMi (insatisfação com os Papéis do Passado e Actuais, respectivamente), distanciadas por referência ao eixo da Dimensão 1 e ao da Dimensão 2 (Fig. 2). Tal indica que quem avalia insatisfatoriamente os papéis do presente não partilha características idênticas a quem avalia insatisfatoriamente os do passado. Estes dados sugerem que, quanto à insatisfação, o passado não determina o presente $e$, no que respeita à multiplicidade de papéis e funções exercidas, a experiência do passado pode influenciar o presente. Em virtude do número restrito de categorias analisadas, este elemento não assume relevo particular; ele abala, contudo, uma percepção de tipo determinista na análise das características psicossociais. 


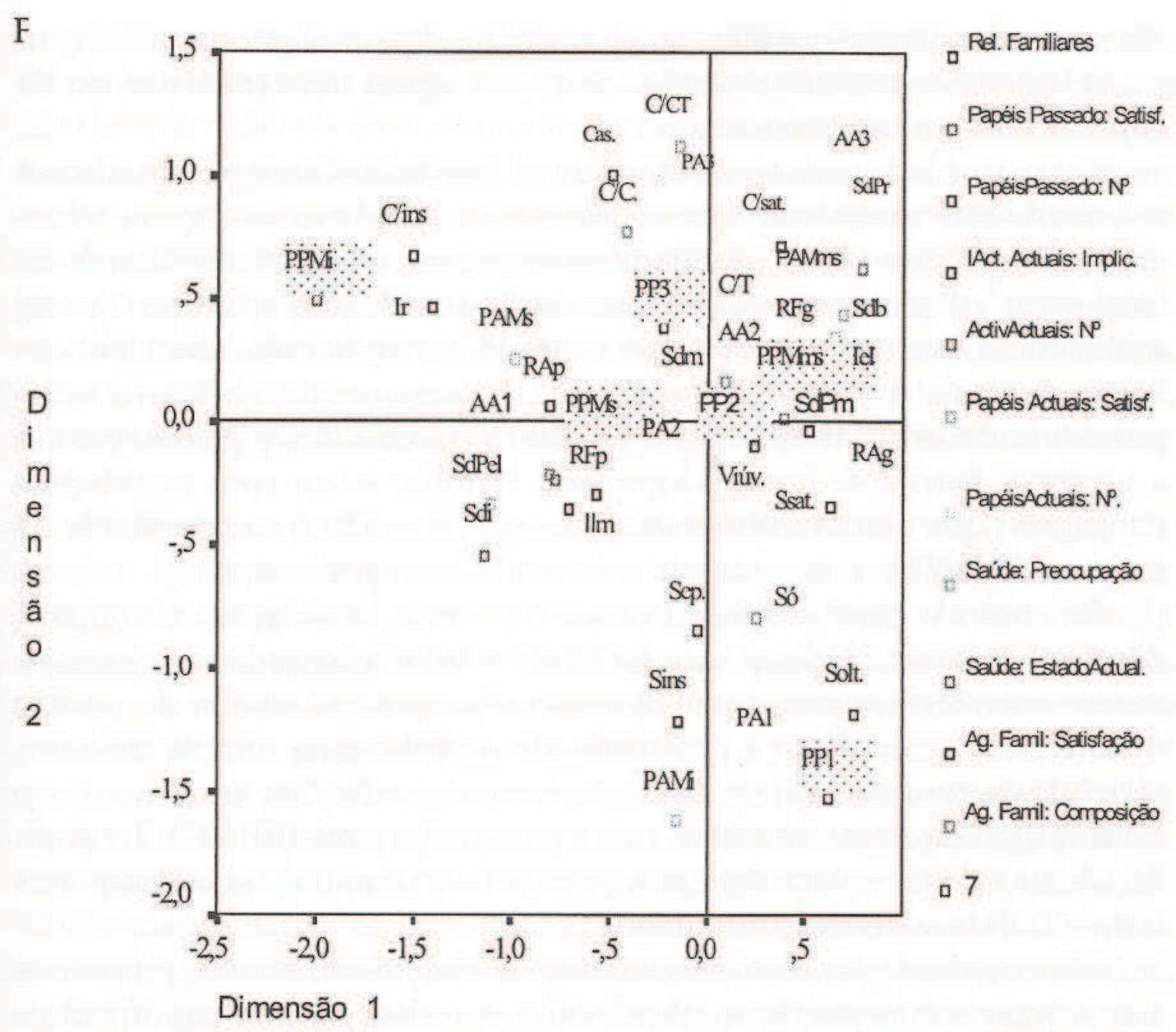

Figura 2

Configuração Topológica do Espaço Psicossocial: Projecção das Variávéis por Categoria

A análise específica de uma eventual estabilidade da avaliação do papel conjugal, vivido no passado e no presente, não pode ser realizada com rigor, dado que esta variável não foi isolada na matriz de input. Contudo, tendo em conta os dados das duas fases de análise, é possível verificar alguma mobilidade temporal na avaliação do grau de satisfação com o papel conjugal. Relativamente ao Grupo 1, há a relevar a intensificação da avaliação negativa das relações conjugais, enquanto no Grupo 3, das mulheres com relação conjugal no passado, $54 \%$ avaliam a relação como muito satisfatória, enquanto a avaliação actual para a mesma categoria sobe para $80 \%$. Com base nestes dados, 
não se pode afirmar, porém, que a mobilidade positiva que neste grupo se indicia decorre de relações conjugais agora mais positivas ou da ruptura dos 'maus casamentos'.

Por outro lado, cruzando a variável Satisfação Conjugal actual com o Estado Civil verifica-se que o casamento na idade avançada não é condição de 'bem-estar', assim como a viuvez não é determinante de 'mal-estar'. Poder-se-ia pensar que o Reduzido BEP (Grupo 1) está associado ao casamento mas, na verdade, ele mostra-se associado ao 'mau-casamento'. Por outro lado, o 'não casamento' revela-se independente do grau de satisfação pessoal e de equilíbrio psicológico. É a vertente Satisfação (com o agregado familiar e/ou com as relações conjugais) que claramente se associa ao BEP, e não a circunstância de ser casada, solteira ou viúva, viver só ou acompanhada.

Em todo o caso e ainda no que se refere às relações conjugais, deve salientar-se também que na idade adulta avançada, e contrariamente aos estereótipos e preconceitos vigentes, os relatos de muitas mulheres testemunham a possibilidade de fruir uma relação de amor satisfatória ou o desejo de estabelecer novas relações, num contexto de conjugalidade ou fora dele, onde possam (re)construir a individualidade na relação intersubjectiva, porventura uma das mais completas e igualitárias vivências humanas.

Centrando agora a análise nas dimensões identificadas, passamos a sintetizar a informação mais relevante ao nível do seu significado e valor diferenciador dos grupos de $\mathrm{BEP}^{10}$.

${ }^{10}$ Por forma a considerar os níveis de homogeneidade ou de diferenciação dos indivíduos, agrupados em função do Bem-Estar Psicológico, teremos de atender aos valores numéricos das dimensões definidas e quantificadas pela HOMALS. Os indicadores da análise de variância univariada (ANOVA) indicam que a Dimensão 1 contribui fortemente para a diferenciação dos grupos $[F(2,66)=44.88$, $p<.000$ ], especificamente do Grupo 1 (BEP-R) face ao Grupo 2 (BEP-VP) e ao Grupo 3 (BEP-G) (ambos significativos a $p<.00$ ); a Dimensão 2 permite diferenciar apenas o Grupo 2 do Grupo $3(p<.04)$. Por seu lado, a Dimensão 3 não permite explicar uma diversidade de comportamentos associada ao BEP ([F (2, $66)=.60, p>.10]$. Renovamos a leitura interpretativa anteriormente formulada a propósito desta terceira dimensão e constatamos que ela revela o carácter descritivo do espaço social em que as participantes se encontram (estado civil, número de papéis e funções) e que este não se mostra importante na diferenciação dos grupos de Bem-Estar Psicológico analisados. 
A Dimensão 1 mostra-se definida, fundamentalmente, pelas variáveis relativas ao grau de (in)satisfação, (des)preocupação e (des)implicação ou envolvimento nas áreas relativas à saúde, à família, aos amigos e à sociedade, num âmbito temporal passado e presente. As componentes relacional e emocional presentes nesta dimensão conferem-lhe um cariz fundamentalmente psicológico, já que congrega as vivências psíquicas globais associadas às condições e posições sociais analisadas, representando o modo como o sujeito se relaciona consigo próprio, com o núcleo familiar e com a esfera social alargada, com destaque para o grau de satisfação que tais relacionamentos envolvem.

Poder-se-á considerar que esta dimensão identifica o modo de pensar, agir e sentir as condições de vida globais, o qual constitui um capital de vivências psicológicas construído a partir da experiência pessoal, onde assentam as referências de identidade básicas, a autoestima, o valor de competência e adequação pessoal, o valor como membro de um grupo familiar e social.

Através desta dimensão podem diferenciar-se as participantes do Grupo 1 (BEP-R) das participantes dos outros dois grupos. As mulheres com reduzido Bem-Estar apresentam um menor capital de recursos fundamentais à harmonia psicológica e à vivência social: o pensar e o agir sobre as condições de vida revela-se insatisfatório do ponto de vista emocional, menos implicado do ponto de vista social e menos gratificante na perspectiva relacional. As participantes do Grupo 2 (BEP-VP) e do Grupo 3 (BEP-G) expressam um conjunto de vivências psicossociais essenciais à identidade e associadas a níveis superiores de bem-estar subjectivo. Nesta dimensão, como atrás salientamos, as experiências de vida durante a meia-idade revelam-se como fundamentais.

A Dimensão 2 é definida pelo estado civil, pelas condições de coabitação (composição do agregado familiar e satisfação), pelo número de papéis e funções actuais e, secundariamente, pelo número de papéis e funções do passado. Esta dimensão identifica, sobretudo, as posições sociais que cada participante ocupa e os valores que lhes estão associados. A vertente mais característica nesta dimensão parece ser a vida actual, centrada na esfera relacional próxima, na esfera familiar. Relativamente à dimensão anterior, que se revela mais expressiva da dinâmica psíquica interna, a Dimensão 2 parece ser mais definidora de características extrínsecas da identidade. A representa- 
ção das categorias indicou-nos que a diferenciação que esta dimensão introduz é de tipo quantitativo, representando, um dos pólos da dimensão, espaços relacionais mais amplos (leque extensivo de papéis e funções durante a vida adulta, anterior e actual, e agregado familiar alargado), por contraste com categorias que correspondem a espaços relacionais mais limitados (agregado de um só elemento e envolvimento num número limitado de papéis e funções). Por outro lado, a análise de variância indica que esta dimensão opera uma diferenciação entre a presença (Grupo 2) ou a ausência (Grupo 3) de vulnerabilidade psicológica, em indivíduos com nível positivo de bemestar subjectivo.

Sendo uma dimensão que está ligada à avaliação actual de aspectos extrínsecos do self e, simultaneamente, diferenciadora de situações de vulnerabilidade psicológica, pode considerar-se que ela identifica o impacto das circunstâncias relacionais actuais no self e as implicações ao nível da qualidade do funcionamento psicológico e da adaptação das participantes. As que apresentam maior vulnerabilidade psicológica (Grupo 2) são aquelas que terão características que as tornam mais dependentes das condições relacionais. O Grupo 3 (BEP-G), quando caracterizado a partir da Dimensão 2, surge como aquele cuja adaptação é menos dependente das posições e condições relacionais no meio familiar e social. Reportando-nos ao Grupo 1 (BEP-R), verificamos que ele não se diferencia dos restantes nesta Dimensão 2, pelo que podemos admitir que o reduzido BEP, e a significativa vulnerabilidade à depressão das participantes que o integram, não seja dependente do contexto relacional actual e que a condição de Bem-Estar seja decorrente de características internas do self, nomeadamente dos recursos psicológicos e da dinâmica relacional identificados pela Dimensão 1, na qual as experiências da vida passada constituem um património muito significativo.

\section{CONCLUSÕES}

A metodologia de análise das variáveis identificadoras do espaço psicossocial permitiu avaliar a importância das experiências de vida na meia-idade no contexto do $\mathrm{BEP}$, da vulnerabilidade à depressão e à descompensação psicológica. Apesar da diversidade dos Espaços Psicossociais identificados, verificaram-se 'áreas de homogeneidade' 
indicadoras de que as vivências psicológicas são construídas a partir das experiências de vida do passado; estas dão textura e densidade psicológica às vivências na idade avançada. O modo como as pessoas se relacionam consigo próprias, com o núcleo familiar e com a esfera social alargada, com destaque para o grau de satisfação com tais relacionamentos, está fortemente associado às experiências do passado.

Mais do que condições específicas de vida, a percepção que as pessoas têm do seu passado está intimamente relacionada com a forma de pensar, agir e sentir as condições de vida do presente e as expectativas de futuro. Sem desvalorizar a importância de outras fases de vida, podemos considerar que as experiências da meia-idade se constituem como importantes ingredientes da identidade e da autoestima, das cognições e dos sentimentos de competência e de adequação pessoal. O capital de recursos desenvolvidos durante a meia-idade parece, assim, ser fundamental à harmonia psicológica, à saúde mental e à satisfação na idade adulta mais tardia.

Para além das variáveis da entrevista aqui analisadas, outras indicam, de um modo coerente, que as dimensões relacional e emocional são dominantes na explicação do BEP nas mulheres estudadas. O BemEstar Psicológico Global, ou genuíno bem-estar, desenha-se, na generalidade das áreas que a entrevista envolve, no sentido de um espaço interpessoal alargado, de um envolvimento em domínios diversos de acção e de uma procura de significado pessoal num contexto relacional. Haverá formas muito diversas de viver e concretizar o BEP na idade adulta avançada, mas a configuração da sua ausência parece ter contornos relativamente homogéneos que, no domínio em análise, se expressam pela maior insatisfação com o passado, pela restrição dos investimentos pessoais e relacionais, pelo menor envolvimento em funções e actividades específicas e, finalmente, pela menor capacidade de antecipar ou procurar mudanças.

Naturalmente que as limitações metodológicas que um estudo transversal impõe e o facto de ser estudada uma amostra muito específica em termos sócio-demográficos chamam a atenção para a impossibilidade de uma generalização dos dados. A amostra estudada integra mulheres nascidas nas décadas de 20 e 30 e a sua história individual acompanha as grandes mudanças que este século conheceu nos valores e nas mentalidades, a vários níveis, um dos quais o da emancipação da mulher com todos os antecedentes (acesso à escolarização 
e profissionalização, autonomia económica e social, etc.) e consequentes, dos quais relevamos, neste contexto, as relações de conjugalidade. Assim, os resultados obtidos poderão ser indicadores pertinentes do universo a que esta amostra pertence, mas não serão, certamente, elementos de referência generalizada para outros contextos, idades ou coortes.

\section{Resumo}

Caracteriza-se o modo como um grupo de mulheres na idade adulta avançada descreve e avalia as vivências psicológicas associadas às condições e circunstâncias da sua vida pessoal e familiar na fase da meia-idade. As memórias do passado e as expectativas de futuro são analisadas na matriz do presente, designadamente no contexto do Bem-Estar Psicológico e/ou da vulnerabilidade à depressão. A amostra estudada integra 69 mulheres com idades compreendidas entre os 65 e os 75 anos, em situação de saúde e de integração social de acordo com os parâmetros correntes de normalidade.

\section{Abstract}

In this study one characterize the way as a group of women, in advanced adult age, describes and evaluates the psychological experiences linked to the conditions and circumstances of their personal and familiar lives in the middle age. The memories of the past and the expectations of the future are analysed in the matrix of the present, namely in the context of the psychological well-being and/or vulnerability to depression. 69 women aged between 65 and 75 old, with health and social conditions integration conditions in accordance with the current normality, compose the studied sample.

\section{REFERÊNCIAS BIBLIOGRÁFICAS}

CHILAND, C. (Org.) (1985). L'entretien clinique (2nd ed.). Paris: Presses Universitaires de France.

INSTITUTO NACIONAL DE ESTATÍSTICA (1999). As gerações mais idosas. Lisboa.

NOVO, R. F. (2000). Para além da eudaimonia: o Bem-Estar Psicológico em mulheres na idade adulta avançada. Lisboa: FPCE. Dissertação de Doutoramento.

NOVO, R. F., DUARTE-SILVA, M. E., \& PERALTA, E. (1997). O bem-estar psicológico em adultos: Estudo das características psicométricas da versão portuguesa das escalas de C. Ryff. In M. Gonçalves, I. Ribeiro, S. Araújo, C. Ma- 
chado, L. Almeida, M. Simões (Orgs.), Avaliação psicológica: Formas e contextos (Vol. V, pp. 313-324). Braga: Associação dos Psicólogos Portugueses.

PERRON, R. (Org.) (1997). La pratique de la psychologie clinique. Paris: Dunod.

RYFF, C. D. (1989a). Beyond Ponce de Leon and life satisfaction: New directions in quest for successful aging. International Journal of Behavioral Development, $12,35-55$.

RYFF, C. D. (1989b). Happiness is everything, or is it? Explorations on the meaning of psychological well-being. Journal of Personality and Social Psychology, 57, 1069-1081.

RYFF, C. D. \& KEYES, C. L. (1995). The structure of psychological well-being revisited. Journal of Personality and Social Psychology, 69, 719-727.

RYFF, C. D. \& SINGER, B. (1998). The contours of positive human health. Psychological Inquiry, 9, 1-28.

SELIGMAN, M. P. \& Cskszentmihalyi, M. (2000). Positive Psychology: An introduction. American Psychologist, 55, 5-14.

VANDEWATER, E. A., OSTROVE, J. M., \& STEWART, A. J. (1997). Predicting women's well-being in midlife: The importance of personality development and social role involvements. Journal of Personality and Social Psychology, 72, $1147-1160$. 


\section{Quadro A}

\section{Variáveis e Categorias da Entrevista: Frequências por Grupo de Bem-Estar Psicológico}

\begin{tabular}{|c|c|c|c|c|c|}
\hline $\begin{array}{l}\text { Variáveis da } \\
\text { Entrevista }\end{array}$ & Categorias & $\begin{array}{l}\text { Grupo 1 } \\
(n=16) \\
\text { Freq. } \% \\
\end{array}$ & $\begin{array}{c}\text { Grupo } 2 * \\
(n=25) \\
\text { Freq. } \% \\
\end{array}$ & 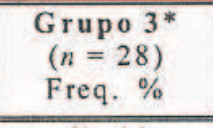 & $\begin{array}{c}\chi^{2+1} \\
(g l, N) \\
p \\
\end{array}$ \\
\hline Estado Civil & $\begin{array}{l}\text { 1- Solteira } \\
2 \text { - Casada } \\
3 \text { - Separada } \\
\text { 4-Viúva }\end{array}$ & $\begin{array}{c}1-6 \\
10-63 \S \S \\
3-19 \\
2-13 \S \\
\end{array}$ & $\begin{array}{l}5-20 \\
5-16 \S \\
4-16 \\
11-44 \\
\end{array}$ & $\begin{array}{c}3-11 \\
10-36 \\
6-21 \\
9-32 \\
\end{array}$ & $\begin{array}{c}11.60 \\
(6,69) \\
.056\end{array}$ \\
\hline $\begin{array}{l}\text { Agreg. Familiar } \\
\text { Composição }\end{array}$ & $\begin{array}{l}\text { 1 - Vive Só } \\
2 \text { - C/ Cônjuge } \\
3 \text { - C/ Cônj.e Terc. } \\
4 \text { - C/ Terceiros }\end{array}$ & $\begin{array}{l}5-31 \\
7-44 \\
3-19 \\
1-6 \\
\end{array}$ & $\begin{array}{r}16-64 \\
4-16 \\
1-4 \\
4-16 \\
\end{array}$ & $\begin{array}{l}14-50 \\
8-29 \\
2-7 \\
4-14\end{array}$ & $n s$ \\
\hline Satisfação & $\begin{array}{l}\text { 1 - Só e Insatisf. } \\
\text { 2-C/Out. } \\
\text { Insatisf. } \\
\text { 3- Só e Satisf. } \\
\text { 4-C/ Out. Satisf. }\end{array}$ & $\begin{array}{l}5-31 \\
7-44 \S \S \\
0 \$ \$ \\
4-25\end{array}$ & $\begin{array}{l}9-36 \\
2-8 \\
7=28 \\
7-28\end{array}$ & $\begin{array}{r}3-11 \S \\
1-4 \S \\
9-32 \\
15-54 \S\end{array}$ & $\begin{array}{l}22.60 \\
(6,69) \\
.000\end{array}$ \\
\hline $\begin{array}{l}\text { Saúde } \\
\text { Estado Actual }\end{array}$ & $\begin{array}{l}\text { 1- Insatisfatório } \\
2 \text { - Médio } \\
3 \text { - Bom } \\
\end{array}$ & $\begin{array}{l}9-56 \S \S \\
5-31 \\
2-12 \S \\
\end{array}$ & $\begin{array}{r}2-8 \\
15-60 \\
8-32 \\
\end{array}$ & $\begin{array}{r}2-7 \S \\
12-43 \\
14-508 \\
\end{array}$ & $\begin{array}{l}21.55 \\
(4,69) \\
.000 \\
\end{array}$ \\
\hline Preocupação & $\begin{array}{l}\text { 1- Reduzida } \\
2 \text { - Moderada } \\
3 \text { - Elevada }\end{array}$ & $\begin{array}{c}1-6 \S \\
4-25 \\
11-69 \S \S\end{array}$ & $\begin{array}{r}4-16 \\
16-64 \\
5-20 \\
\end{array}$ & $\begin{array}{l}15-54 \S \S \\
10-36 \\
3-11 \S \\
\end{array}$ & $\begin{array}{c}27.48 \\
(4,69) \\
.000 \\
\end{array}$ \\
\hline $\begin{array}{l}\text { Papéis/Funções Act. } \\
\text { N. }{ }^{\circ} \text { Papéis/Funções }\end{array}$ & $\begin{array}{l}1-0 \text { e } 1 \\
2-2 \\
3-3 \\
4-4 \text { e } 5 \\
\end{array}$ & $\begin{array}{c}4-25 \\
4-25 \\
8-50 \\
(0) \\
\end{array}$ & $\begin{array}{c}10-40 \\
11-44 \\
4-16 \S \\
(0)\end{array}$ & $\begin{array}{c}5-11 \\
11-39 \\
9-32 \\
(3-11) \\
\end{array}$ & $\begin{array}{l}11.51 \\
(4,66) \\
.074\end{array}$ \\
\hline $\begin{array}{l}\text { Papel Conjugal } \\
\text { Grau Satisfação }\end{array}$ & $\begin{array}{l}\text { 1- Pouco Satisf. } \\
\text { 2- Satisfatório } \\
\text { 3-Muito Satisf. }\end{array}$ & $\begin{aligned} & 4-40 \\
& 6-60 \\
& 0 \$ 8\end{aligned}$ & $\begin{aligned}-20 \\
2-40 \\
2-40\end{aligned}$ & $\begin{aligned} & 1-10 \\
& 1-10 \S \\
& 8-80 \S \S \\
&\end{aligned}$ & $\begin{array}{l}14.07 \\
(4,25) \\
.007\end{array}$ \\
\hline $\begin{array}{l}\text { Papéis Maternais } \\
\text { Grau Satisfação }\end{array}$ & $\begin{array}{l}\text { 1- Pouco Satisf. } \\
\text { 2- Satisfatório } \\
\text { 3- Muito Satisf. }\end{array}$ & $\begin{array}{r}(1-6) \\
12-75 \\
0 \$ \$ \\
\end{array}$ & $\begin{array}{r}(1-4) \\
6-24 \\
11-44 \\
\end{array}$ & $\begin{array}{c}(0) \\
5-18 \S \S \\
18-64 \S \S \\
\end{array}$ & $\begin{array}{c}21.58 \\
(2,52) \\
.000 \\
\end{array}$ \\
\hline $\begin{array}{l}\text { Funções } \\
\text { Grau Satisfação }\end{array}$ & 3-Muito Satisf. & 0 & $4-16$ & $9-32$ & - \\
\hline $\begin{array}{l}\text { Papéis/Funçōes do } \\
\text { Passado: } \\
\text { N." Papéis/Funções }\end{array}$ & $\begin{array}{c}1 \\
2 \\
3 \\
(4) \\
\end{array}$ & $\begin{array}{l}1-6 \\
8-50 \\
7-44 \\
(0)\end{array}$ & $\begin{array}{c}5-20 \\
8-32 \\
11-44 \\
(1-4)\end{array}$ & $\begin{array}{l}2-7 \\
11-39 \\
13-46 \\
(2-7) \\
\end{array}$ & $n s$ \\
\hline $\begin{array}{l}\text { Papel Conjugal } \\
\text { Grau Satisfação }\end{array}$ & $\begin{array}{l}\text { 1-Pouco Satisfat. } \\
\text { 2- Satisfatório } \\
\text { 3-Muito Satisfat. }\end{array}$ & $\begin{array}{c}3-19 \\
12-75 \$ \$ \\
0 \quad \$ \$ \\
\end{array}$ & $\begin{array}{r}3-12 \\
6-24 \\
11-44 \\
\end{array}$ & $\begin{array}{r}5-18 \\
5-18 \S \S \\
15-54 \S \\
\end{array}$ & $\begin{array}{c}20.26 \\
(4,60) \\
.000 \\
\end{array}$ \\
\hline $\begin{array}{l}\text { Papel Maternal } \\
\text { Grau Satisfação }\end{array}$ & $\begin{array}{l}\text { 1- Pouco Satisfat. } \\
\text { 2- Satisfatório } \\
\text { 3- Muito Satisfat. }\end{array}$ & $\begin{array}{l}(0) \\
4-25 \\
9-56 \\
\end{array}$ & $\begin{array}{c}(0) \\
4-16 \\
14-56 \\
\end{array}$ & $\begin{array}{c}(0) \\
2-7 \\
21-75 \\
\end{array}$ & $n s$ \\
\hline $\begin{array}{l}\text { Funções: } \\
\text { Grau Satisfação }\end{array}$ & \begin{tabular}{|l} 
(1-Pouco Satisfat.) \\
2-Satisfatório \\
3-Muito Satisfat. \\
\end{tabular} & $\begin{array}{l}(2-12) \\
6-37 \S \\
3-19 \S \S \\
\end{array}$ & $\begin{array}{c}(0) \\
7-28 \\
12-48 \\
\end{array}$ & $\begin{array}{c}(0) \\
8-29 \\
13-46 \\
\end{array}$ & $\begin{array}{c}9.84 \\
(2,49) \\
.042 \\
\end{array}$ \\
\hline
\end{tabular}

(Quadro continua)

Nota. * Grupo 1 - BEP-R (Bem-Estar Psicológico Reduzido); Grupo 2 - BEP-VP (BemEstar e Vulnerabilidade Psicológica); Grupo 3 - BEP-G (Bem-Estar Psicológico Global).

** Teste de Homogeneidade $\chi^{2}$. As categorias assinaladas entre parêntesis não foram integradas na análise por apresentarem frequências baixas ou nulas.

$\S$ e $\S \S$ - Sinalizam as categorias com valores residuais (estandardizados e ajustados) significativos a $p<.05$ e $p<.01$, respectivamente; indicam-se a negro forte os valores residuais de sinal negativo e a negro fraco os valores de sinal positivo. 
Quadro A (Cont.)

Variáveis e Categorias da Entrevista: Frequências por Grupo de Bem-Estar Psicológico

\begin{tabular}{|c|c|c|c|c|c|}
\hline $\begin{array}{l}\text { Variáveis da } \\
\text { Entrevista }\end{array}$ & Categorias & $\begin{array}{l}\text { Grupo } 1^{\circ} \\
(n=16) \\
\text { Freq. } \%\end{array}$ & $\begin{array}{l}\text { Grupo } 2^{*} \\
(n=25) \\
\text { Freq. } \%\end{array}$ & $\begin{array}{l}\text { Grupo } 3 * \\
(n=28) \\
\text { Freq. } \%\end{array}$ & $\begin{array}{c}\chi^{2 *} \\
(g l, N) \\
p\end{array}$ \\
\hline \begin{tabular}{|c|} 
A ctividades Actuais \\
N. ${ }^{\circ}$ de Actividades
\end{tabular} & $\begin{array}{l}1-1 \\
2-2 \\
3-3 \\
4-(4) \\
\end{array}$ & $\begin{array}{c}11-69 \S \S \\
5-31 \\
0 \$ \S \\
(0)\end{array}$ & $\begin{array}{c}10-40 \\
12-48 \\
3-12 \\
(0)\end{array}$ & $\begin{array}{r}4-14 \\
19-68 \S \\
4-14 \\
(1-4) \\
\end{array}$ & $\begin{array}{c}14,04 \\
(4,68) \\
.007\end{array}$ \\
\hline Grau de Implicação & $\begin{array}{l}\text { 1- Reduzida } \\
\text { 2- Moderada } \\
3 \text { - Elevada }\end{array}$ & $\begin{array}{r}(2-12) \\
11-69 \S \S \\
3-19 \S \S \\
\end{array}$ & $\begin{array}{r}(1-4) \\
8-32 \\
16-64 \\
\end{array}$ & $\begin{array}{c}(0) \\
6-21 \S \\
22-79 \S \S \\
\end{array}$ & $\begin{array}{c}16.43 \\
(2,66) \\
.002 \\
\end{array}$ \\
\hline \multirow[t]{2}{*}{$\begin{array}{r}\text { Relações Interpessoais } \\
\text { Familiares }\end{array}$} & $\begin{array}{l}\text { 1- Distantes } \\
2 \text { - S/Envolv. Pessoal } \\
3 \text { - Gratificantes }\end{array}$ & $\begin{array}{r}(1-6) \\
10-62 \\
5-31 \\
\end{array}$ & $\begin{array}{c}(1-4) \\
8-32 \\
16-64 \\
\end{array}$ & $\begin{array}{r}(1-4) \\
8-29 \\
19-68 \\
\end{array}$ & $n s$ \\
\hline & \begin{tabular}{|l} 
- Distantes \\
2- S/Envolv. Pessoal \\
3- Gratificantes
\end{tabular} & $\begin{array}{c}(0) \\
15-94 \S \S \\
1-6 \S \S\end{array}$ & $\begin{array}{c}(0) \\
8-32 \\
17-68\end{array}$ & $\begin{array}{c}(0) \\
4-14 \S \S \\
24-86 \S \S\end{array}$ & $\begin{array}{c}27.83 \\
(2,69) \\
.000\end{array}$ \\
\hline Religião & $\begin{array}{l}\text { 1-S/Crença } \\
\text { 2-C/Crença S/Prática Pública } \\
\text { 3-C/Crença C/Prática Pública }\end{array}$ & $\begin{array}{r}(1-6) \\
11-69 \S \\
4-25 \S \\
\end{array}$ & $\begin{array}{r}(3-12) \\
9-36 \\
13-52 \\
\end{array}$ & $\begin{array}{r}(3-11) \\
7-25 \$ \\
18-64 \$ \\
\end{array}$ & $\begin{array}{c}8.52 \\
(2,62) \\
.074 \\
\end{array}$ \\
\hline \multirow{2}{*}{$\begin{array}{l}\text { Invest. Fu tu ro } \\
\text { Manutenção vs Mudançą } \\
\text { Áreas }\end{array}$} & $\begin{array}{l}\text { 1- Actividades Actuais } \\
\text { 2- Novas Actividades }\end{array}$ & $\begin{array}{r}11-69 \\
5-31 \\
\end{array}$ & $\begin{array}{r}17-68 \\
8-32 \\
\end{array}$ & $\begin{array}{l}17-61 \\
11-39 \\
\end{array}$ & $n s$ \\
\hline & $\begin{array}{l}\text { 1- Área Pessoal } \\
2 \text { - Área Interpessoal }\end{array}$ & $\begin{array}{r}14-87 \S \S \\
2-12 \S \S\end{array}$ & $\begin{array}{l}11-44 \\
14-56\end{array}$ & $\begin{array}{r}8-29 \S \S \\
20-71 \S \S\end{array}$ & $\begin{array}{c}14.40 \\
(2,69) \\
.001\end{array}$ \\
\hline
\end{tabular}

Nota. * Grupo 1 - BEP-R (Bem-Estar Psicológico Reduzido); Grupo 2 - BEP-VP (BemEstar e Vulnerabilidade Psicológica); Grupo 3 - BEP-G (Bem-Estar Psicológico Global).

** Teste de Homogeneidade $\chi^{2}$. As categorias assinaladas entre parêntesis não foram integradas na análise por apresentarem frequências baixas ou nulas.

$\S$ e $\S \S$ - Sinalizam as categorias com valores residuais (estandardizados e ajustados) significativos a $p<.05$ e $p<.01$, respectivamente; indicam-se a negro forte os valores residuais de sinal negativo e a negro fraco os valores de sinal positivo. 


\section{Quadro B}

Variáveis e Categorias dos Dados da Entrevista para Análise HOMALS

\begin{tabular}{|c|c|c|c|}
\hline Blocos da Entrevista: & Categorias* & Códigos & \\
\hline Estado Civil & $\begin{array}{l}\text { 1 - Solteira } \\
2 \text { - Casada/U.Facto } \\
3 \text { - Separada } \\
4 \text { - Viúva }\end{array}$ & & $\begin{array}{l}\text { Solt } \\
\text { Cas } \\
\text { Sep } \\
\text { Viúv }\end{array}$ \\
\hline \multirow[t]{2}{*}{ Agregado Familiar: } & $\begin{array}{l}\text { I - Vive Só } \\
2 \text { - C/ Cônjuge } \\
3 \text { - C/ Cônjuge e Terceiros } \\
4-\mathrm{C} / \text { Terceiros }\end{array}$ & $\begin{array}{l}\mathrm{C} / \mathrm{C} \\
\mathrm{C} / \mathrm{CT} \\
\mathrm{C} / \mathrm{T}\end{array}$ & Só \\
\hline & $\begin{array}{l}\text { 1-Vive Só e Insatisfeita } \\
\text { 2-Vive c/ Outros e Insatisfeita } \\
\text { 3-Vive Só e Satisfeita } \\
4 \text { - Vive c/ Outros e Satisfeita }\end{array}$ & $\begin{array}{l}\text { s } \\
\text { Ssat } \\
\text { C/sat }\end{array}$ & $\begin{array}{l}\text { Sins } \\
C / \text { in }\end{array}$ \\
\hline Estado Actual & $\begin{array}{l}\text { 1- Mau/Insatisfatório } \\
2 \text { - Médio } \\
\text { 3-Bom/Muito Bom }\end{array}$ & $\begin{array}{l}\text { Sdi } \\
\text { Sdb }\end{array}$ & $\mathrm{Sdm}$ \\
\hline Preocupação & $\begin{array}{l}\text { - Reduzida } \\
2 \text { - Moderada } \\
3 \text {-Elevada }\end{array}$ & $\begin{array}{l}\text { SdPr } \\
\text { m } \\
\text { SdPel }\end{array}$ & $\mathrm{SdP}$ \\
\hline \multirow{2}{*}{$\begin{array}{r}\text { Papéis/Funções Actuais: } \\
\text { N. de Papéis e Funções } \\
\text { Grau de Satisfação (Média) }\end{array}$} & $\begin{array}{|ll|}1-0 \text { e } 1 & \\
& 2-2 \\
& 3-3 \text { e } 4 \\
\end{array}$ & $\begin{array}{l}\text { PA1 } \\
\text { PA3 }\end{array}$ & PA2 \\
\hline & $\begin{array}{l}\text { 1 - Insatisfatório } \\
2 \text { - Satisfatório } \\
3 \text { - Muito Satisfatório }\end{array}$ & $\begin{array}{l}\text { PAMi } \\
\text { Ms } \\
\text { PAMms }\end{array}$ & PA \\
\hline \multirow{2}{*}{$\begin{array}{r}\text { Papéis/Funçōes do Passado: } \\
\text { N. }{ }^{\circ} \text { de Papéis e Funções } \\
\text { Grau de Satisfação (Média) }\end{array}$} & \begin{tabular}{|ll}
$1-1$ & $2-2$ \\
& $3-3$ e 4 \\
& 3
\end{tabular} & $\begin{array}{l}\text { PP1 } \\
\text { PP3 }\end{array}$ & PP2 \\
\hline & $\begin{array}{l}\text { - Insatisfatório } \\
2 \text { - Satisfatório } \\
3 \text { - Muito Satisfatório }\end{array}$ & $\begin{array}{l}\text { PPMi } \\
\text { Ms } \\
\text { PPMms }\end{array}$ & PP \\
\hline $\begin{array}{l}\text { Actividades Actuais } \\
\mathrm{N}\end{array} .^{\circ}$ de Actividades & 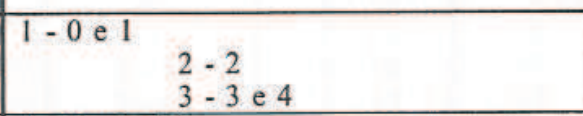 & AA1 & AA2 \\
\hline Grau de Implicação & $\begin{array}{l}\text { 1 - Reduzida } \\
2 \text { - Moderada } \\
\text { 3-Elevada } \\
\end{array}$ & Ir & Im \\
\hline \multirow[t]{2}{*}{$\begin{array}{l}\text { Relações Interpessoais } \\
\text { Relações Familiares }\end{array}$} & $\begin{array}{c}\text { - Pobres (Inexistentes ou s/ } \\
\text { Envolvimento Pessoal) } \\
2 \text { - Gratificantes } \\
\end{array}$ & RFp & $\mathrm{RFg}$ \\
\hline & $\begin{array}{c}\text { - Pobres (Inexistentes ou s/ } \\
\text { Envolvimento Pessoal) } \\
2 \text { - Gratificantes } \\
\end{array}$ & RAp & RAg \\
\hline Religião & $\begin{array}{l}\text { - S/Crença Religiosa } \\
2 \text { - C/ Crença e s/ Prática Religiosa } \\
3-\text { C/ Prática Religiosa }\end{array}$ & $\begin{array}{l}\mathrm{S} / \mathrm{R} \\
\mathrm{R} \\
\mathrm{C} / \mathrm{PR}\end{array}$ & $\mathrm{S} / \mathrm{P}$ \\
\hline \multirow{2}{*}{$\begin{array}{r}\text { Áreas de Investimento Futuro } \\
\text { Manutenção vs Mudança } \\
\text { Área dos Interesses }\end{array}$} & $\begin{array}{l}\text { 1- Manutenção Actividades Actuais } \\
2 \text { - Orientaça } \mathrm{p} / \text { Novas Actividades }\end{array}$ & $\begin{array}{l}\text { MAct } \\
\text { NAct }\end{array}$ & \\
\hline & $\begin{array}{l}1 \text { - Centradas na Esfera Pessoal } \\
2 \text { - Vocacionados p/ärea } \\
\text { Interpessoal }\end{array}$ & Apes & Aint \\
\hline
\end{tabular}

Nota. ${ }^{*}$ Os critérios de categorização estão descritos detalhadamente em Novo, 2000. 